\title{
The Influence of Financial Agglomeration on the Export Trade in the Guangdong-Hong Kong-Macao Greater Bay Area: An Analysis Based on Mediation Effect of Technological Innovation
}

\author{
Zhisen Zeng ${ }^{1}$, Huixian Zeng ${ }^{1}$, \& Jingyu $\mathrm{Wu}^{1}$ \\ ${ }^{1}$ Finance Department of International Business School, Jinan University, Guangdong, 519070, China \\ Correspondence: Zhisen Zeng, Finance Department of International Business School, Jinan University,Qianshan Road \\ 206\#, Zhuhai City,Guangdong province,Post No.519070,China.
}

Received: May 21, 2021

doi:10.11114/aef.v8i3.5265
Accepted: June 4, $2021 \quad$ Available online: June 18, 2021

URL: https://doi.org/10.11114/aef.v8i3.5265

\begin{abstract}
So far, the relation between financial agglomeration and export trade is complex and there are few related studies. However, research on this topic will be of great value to the development of the Guangdong-Hong Kong-Macau Greater Bay Area (the Greater Bay Area). This paper aims to use the mediation model to analyze the role of technological innovation as an mediator variable between financial agglomeration and export trade. Based on the relevant data of the Greater Bay Area from 2009 to 2018, regression analysis was performed using the three equations of the mediation model. The mediator variable was then replaced to conduct a robustness test, and it was found that there is indeed an mediation effect; technological innovation acts as an mediator variable between financial agglomeration and export trade. Therefore, it can be concluded that the financial agglomeration in the Greater Bay Area can effectively promote technological innovation, while technological innovation will inhibit exports to a certain extent.
\end{abstract}

Keywords: financial agglomeration, export trade, innovation, mediation model

\section{Introduction}

As the cities of the Greater Bay Area become more integrated, the financial sector has seen vigorous development, which leads to a noticeable phenomenon known as financial agglomeration. The impact of financial agglomeration on innovation is diverse. Studies by many scholars have shown that financial agglomeration can effectively promote innovation and improve regional technological level; however, some other scholars' studies demonstrate that financial agglomeration may impair innovation. Thus, the effect of financial agglomeration on innovation may be inconsistent depending on specific regional features. On one hand, the Greater Bay Area, one of the major innovation hub in Asia, has promoted the development of science and technology with full power under the support of national policies. However, whether financial agglomeration promotes the key element, innovation, of this development in tech industry remains to be questionable. On the other hand, the Greater Bay Area is also an important hub for foreign trade, which contributes greatly to the overall economic performance of China. Scholars have not yet reached a unified conclusion on whether scientific and technological innovation will promote or inhibit the development of export trade. The research of Zeng (2021) shows that the financial agglomeration of the Greater Bay Area will have a certain inhibitory effect on export trade. This article is a further study aimed at exploring the intermediary role of technological innovation in the relation between financial agglomeration and export trade.

\section{Literature Review}

\subsection{Research on the Relation Between Financial Agglomeration and Innovation}

Regarding the effect of financial agglomeration on innovation, scholars had different viewpoints. Some believed that financial agglomeration could promote innovation, the others, on the contrary, considered this phenomenon as an obstacle to innovation. Schumpeter (1912) first proposed that financial agglomeration could promote innovation; Jin (2012) found that the main source of funding for technological innovation activities was bank loan, hence proving that financial agglomeration could promote Technological innovation; Li, Ran and Zheng (2017) proved that finance could promote innovation from the perspective of the scale, structure and efficiency of financial development.

Some scholars, however, after conducting research on different regions, found that the effect of financial agglomeration 
on innovation was not absolute, and it had a strong correlation to geographical conditions. Wang and Bai (2017) used the Tobit model to conduct research in different region of China and found that while financial agglomeration played an important role in promoting technological innovation in eastern and western parts of China, its effect was not significant in the central regions of China; Li and Deng (2017), however, came to the opposite conclusion, proposing that financial agglomeration failed to promote technological development in regions where strong financial agglomeration had already exist (i.e., financial agglomeration has diminishing marginal effect); Yan and Xu (2019) conducted separate studies on developed and underdeveloped regions, and concluded that in underdeveloped regions, financial agglomeration had a greater effect on technological innovation.

Some scholars also found a threshold effect when studying the relation between financial agglomeration and innovation. Yan and $\mathrm{Xu}$ (2019) used impulse response model to prove that low financial agglomeration in the initial stage was not conducive to technological innovation. Only when the agglomeration developed to a certain level can it promote technological innovation. Zhang (2019) found a similar Conclusion; However, Xiu, Zhu, and Liu (2019) came to the opposite conclusion: when the agglomeration level falled below the threshold, the lower it was, the more favorable it would be for technological innovation.

Scholars still had different opinions on the impact of financial agglomeration on innovation, which probably stemmed from the uncertain effect of financial agglomeration (i.e., producing different outcomes under different circumstances). This further emphasized the importance of conducting such research on the Greater Bay Area, as the conclusion of previous studies might not be suitable for this particular region.

\subsection{Research on the Relation between Innovation and Export Trade}

Scholars had no unified conclusion on the relationship between innovation and export trade as well. Some scholars believed that innovation can effectively promote the development of export trade, some hold contrary opinion, claiming that innovation can inhibit the development of export trade, and the others proposed a two-way relationship between these two factors. Yao and Fang (2007) analyzed the output and input of technological innovation, and concluded that innovation can promote export trade; Zou, Qi, and Xu (2008) studied the effect of export trade on technological innovation, finding that export trade can promote technological innovation; Yu (2011) then used the simultaneous equations method to prove that there was a two-way promotion effect between export trade and innovation.

Some scholars also pointed out some problems of current studies on innovation and export trade. Yu and Liu (2008) divided innovation into domestic and foreign innovations, and found that while foreign innovation had a significant role in promoting China's export trade, domestic innovation had no significant effect. This might be due to the fact that China's domestic innovations mainly focused on practical application; Wang and Guan (2009) pointed out that since only a few enterprises in China owned intellectual property rights and China's economy still relied heavily on processing trade, a mismatch between China's technological innovations and the demand of the market might exist, which weakened the export trade.

Therefore, it can be concluded that the impact of innovation on export trade may be inconsistent in different regions and under various circumstances. Because of the existence of this uncertainty, conducting research based on the characteristic of a particular region is highly necessary.

Based on the research mentioned above, it can be concluded that financial agglomeration may increase production efficiency or product quality by promoting scientific and technological innovation, thus contribute to the growth of export trade; however, financial agglomeration may also inhibit innovation, hence hinder the growth of export trade. Moreover, agglomeration in the financial sector may have other effects, leading to more complicated results. Although existing literature has already proposed some theories regarding the relation between financial agglomeration and export trade, the unique features of the Greater Bay Area have not been taken into account. Therefore, by introducing technological innovation, an mediator variable, and focusing on the feature of this emergent metropolitan, this paper aims to fill the gap and provide a unique insight to the development of the Greater Bay Area.

\subsection{Status Quo of Financial Agglomeration in the Greater Bay Area}

The financial agglomeration location quotients of cities in the Greater Bay Area are shown in Table 1. When the location quotient of one particular city falls below 1, the financial agglomeration level of that city is lower than the average of all cities. When the quotient is greater than 1, it illustrates a financial agglomeration level greater than average. 
Table 1. Location quotient of cities in the Greater Bay Area (Note 1)

\begin{tabular}{cccccccccccc}
\hline City & 2009 & 2010 & 2011 & 2012 & 2013 & 2014 & 2015 & 2016 & 2017 & 2018 & Average \\
\hline Shenzhen & 1.418 & 1.420 & 1.441 & 1.407 & 1.399 & 1.345 & 1.317 & 1.296 & 1.222 & 1.168 & 1.343 \\
Guangzhou & 0.653 & 0.666 & 0.740 & 0.774 & 0.783 & 0.848 & 0.843 & 0.847 & 0.854 & 0.839 & 0.785 \\
Foshan & 0.367 & 0.355 & 0.402 & 0.413 & 0.418 & 0.455 & 0.398 & 0.401 & 0.408 & 0.408 & 0.402 \\
Zhuhai & 0.487 & 0.498 & 0.543 & 0.602 & 0.656 & 0.622 & 0.674 & 0.681 & 0.684 & 0.665 & 0.611 \\
Huizhou & 0.324 & 0.331 & 0.327 & 0.326 & 0.352 & 0.342 & 0.361 & 0.410 & 0.465 & 0.486 & 0.372 \\
Dongguan & 0.442 & 0.439 & 0.413 & 0.428 & 0.462 & 0.626 & 0.597 & 0.590 & 0.567 & 0.570 & 0.513 \\
Jiangmen & 0.303 & 0.306 & 0.388 & 0.401 & 0.423 & 0.553 & 0.529 & 0.488 & 0.474 & 0.466 & 0.433 \\
Zhongshan & 0.416 & 0.403 & 0.386 & 0.441 & 0.456 & 0.503 & 0.497 & 0.514 & 0.541 & 0.533 & 0.469 \\
Zhaoqing & 0.324 & 0.279 & 0.280 & 0.285 & 0.279 & 0.268 & 0.262 & 0.283 & 0.333 & 0.353 & 0.295 \\
Hong Kong & 1.688 & 1.723 & 1.716 & 1.712 & 1.739 & 1.641 & 1.621 & 1.595 & 1.702 & 1.737 & 1.687 \\
Macau & 0.116 & 0.540 & 0.455 & 0.462 & 0.450 & 0.427 & 0.553 & 0.637 & 0.608 & 0.556 & 0.480 \\
\hline
\end{tabular}

It can be seen that the level of financial agglomeration in Shenzhen and Hong Kong has been considerably high, while other cities have not even reached the average. This illustrates that the agglomeration process mainly occurs in two cities, Shenzhen and Hong Kong. Though the performances of other cities were far worse than Shenzhen and Hong Kong a decade ago, rapid development has been seen in the past decade. Supportive national policies have contributed greatly to this trend, and such trend is believed to push the financial agglomeration along the bay even further.

\subsection{Status Quo of Innovation in the Greater Bay Area}

Patents are important indicators to measure the innovation level of a country or region. According to the Guangdong-Hong Kong-Macao Greater Bay Area Synergy Innovation Development Report(2019) released by the GDI (Guangzhou Daily Data and Digit Institute), the total number of patents in the Greater Bay Area has been rising at an annual average of 33.68\% from 2014 to 2018. Moreover, the Greater Bay Area ranks first among the four major bay areas in the world regarding total patent number. Although the level of innovation differs from city to city, the overall level of innovation in the Greater Bay Area is constantly improving.

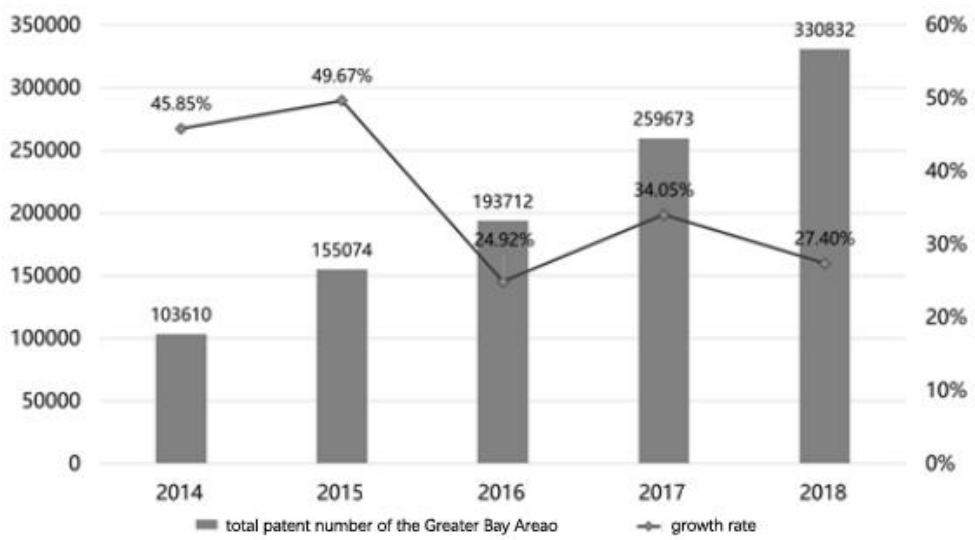

Figure 1. Total patent number of the Greater Bay Area and its growth (Note 2)

\subsection{Status Quo of Export Trade in the Greater Bay Area}

The Greater Bay Area has long been one of the major ports of China. The export trade of the Greater Bay Area has seen an increase of $68.8 \%$ in the last decade, however, that figure is far lower than the national export growth rate (98.4\%). In addition, the proportion of total national exports the Greater Bay Area accounted for has dropped approximately $6 \%$ (from $43.79 \%$ in 2009 to $37.26 \%$ in 2018).

This phenomenon may be attributed to the country's efforts to solve the problem of regional development imbalance in recent years. The export industry of many inland cities has seen rapid development as labor costs are lower. In addition, as technological level gradually improves in the Greater Bay Area, it gradually lost its competitive edge in labor-intensive export trade while gaining competence in technology-intensive export industries. Though growth of export trade slowed in the Greater Bay Area in the past decade, this does not indicate that the Greater Bay Area is facing a huge challenge in the export trade. On the contrary, the Greater Bay Area is undergoing industrial upgrading and making it more appealing to global talents. 


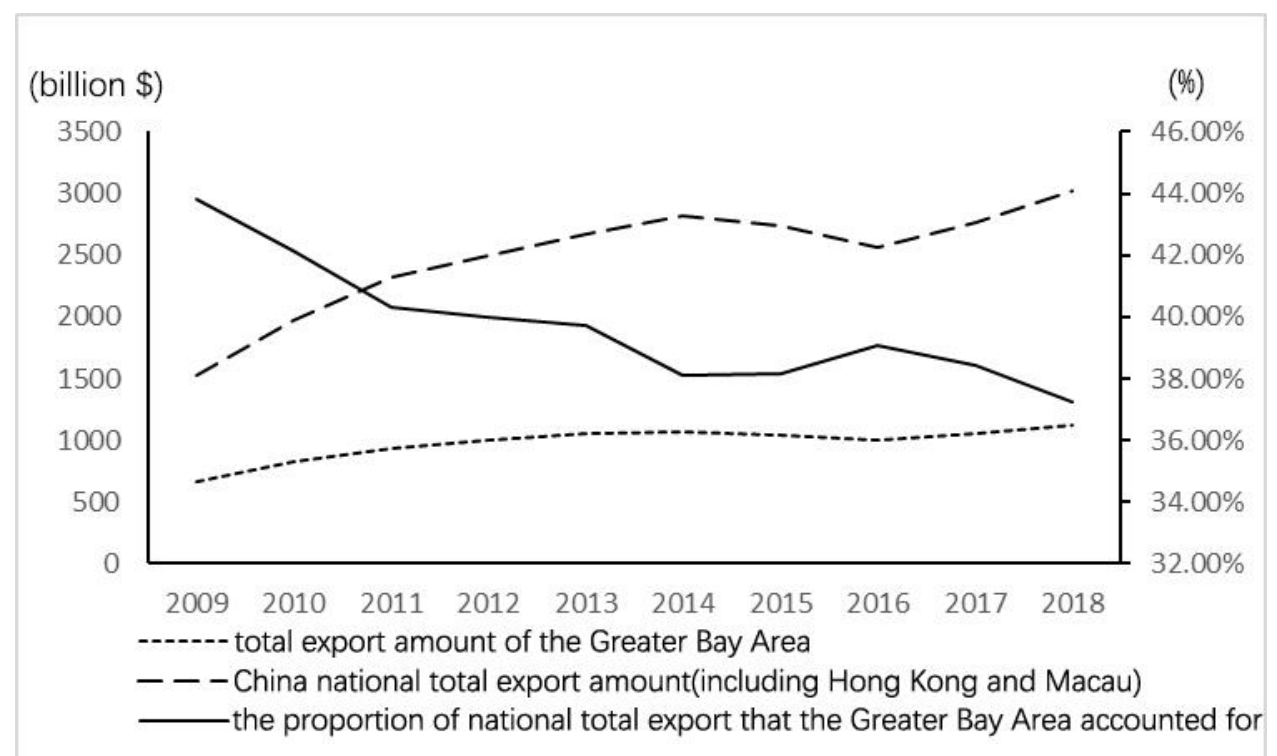

Figure 2. Export trade of the Greater Bay Area (including Macau and Hong Kong) and its proportion to national total export (Note 3)

\section{Method}

\subsection{Theoretical Analysis and Research Assumptions}

\subsubsection{Mediation Effect}

In statistics, a mediation model seeks to identify and explain the mechanism that underlies an observed relationship between an independent variable and a dependent variable via the inclusion of a third hypothetical variable, known as a mediator variable (also a mediating variable, intermediary variable, or intervening variable). Rather than a direct causal relationship between the independent variable and the dependent variable, a mediation model proposes that the independent variable influences the (non-observable) mediator variable, which in turn influences the dependent variable. Thus, the mediator variable serves to clarify the nature of the relationship between the independent and dependent variables.

The mediation effect can be illustrated using the following figure, where $\mathrm{X}$ denotes the independent variable, $\mathrm{Y}$ the dependent variable, and $\mathrm{M}$ the intermediary variable.

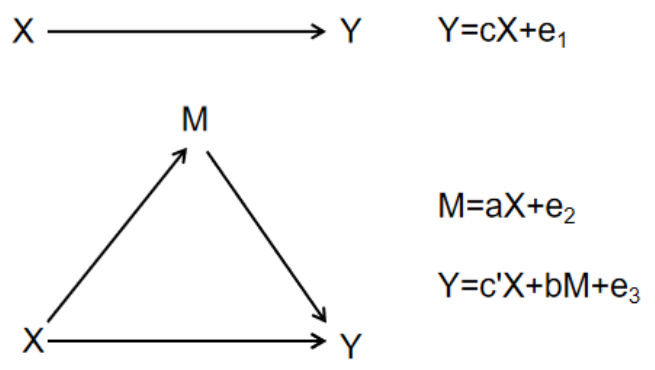

Figure 3. Schematic diagram of the mediation effect mechanism

In the schematic diagram shown above, c represents the total effect $(c=a b+c$ '), c' represents the direct effect, $a b$ represents the indirect effect, and e1, e2, and e3 are error terms. 


\subsubsection{Analysis of the Relation Between Financial Agglomeration and Export Trade}

One of the typical effects of financial agglomeration is promoting technological innovation, which then has an influence on the overall economic performance of a particular region. According to the degree of factor intensiveness, the export enterprises of the Greater Bay Area fall into three categories: labor-intensive enterprises, technology-intensive enterprises and capital-intensive enterprises. This article then further explores whether a mediator variable, technological innovation, exists between the financial agglomeration and export trade.

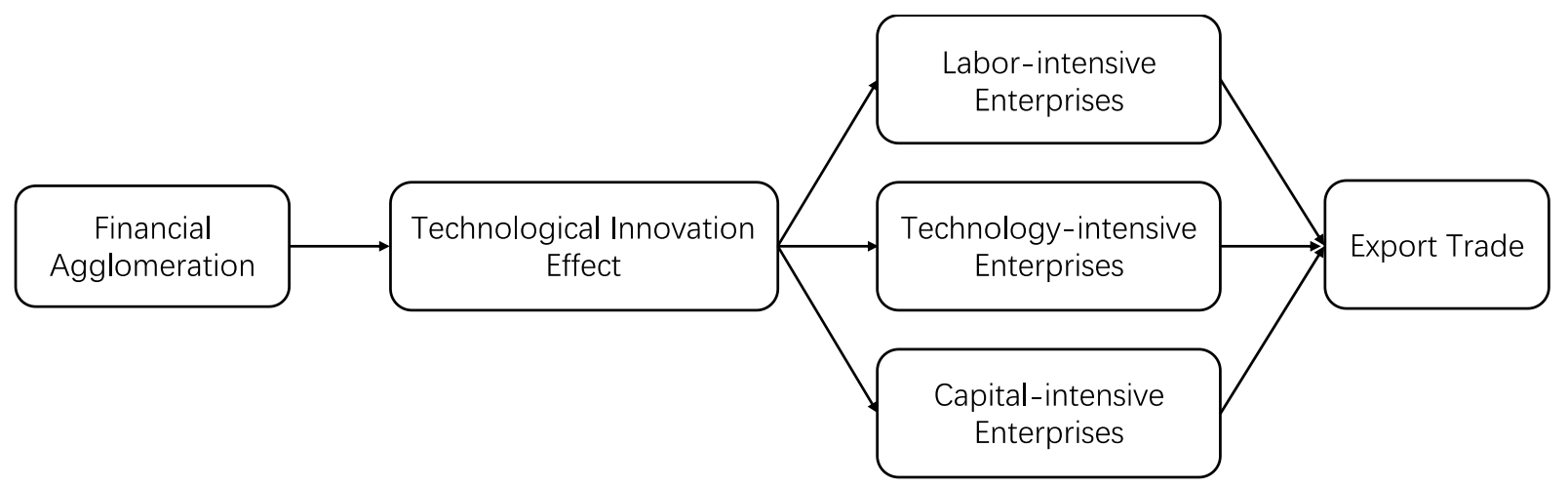

Figure 4. Schematic diagram of the relation between financial agglomeration and export trade

Thanks to its technological innovation effect, financial agglomeration is likely to promote technological innovation (as shown in the diagram above), thereby affecting the output of the three types of enterprises. However, its impact on overall export trade is still uncertain and further research is required. It is also difficult to determine whether the technological innovation effect of financial agglomeration has an influence on export trade (i.e., whether technological innovation is an intermediary variable). Therefore, further empirical tests will be needed in order to determine whether technological innovation is indeed a mediator variable between financial agglomeration and export trade, and whether this mediation effect has a positive or negative impact on export trade.

\subsubsection{Reseach Assumptions}

Taking the relevant theoretical analysis into consideration, the following hypothesis is made for this study: technological innovation in the Greater Bay Area is an intermediary variable between financial agglomeration and export trade, and financial agglomeration can promote export trade.

\subsection{Research Samples and Data Sources}

This paper selects panel data from 2009 to 2018 in the Greater Bay Area and selects several indicators that have significant influence on export trade. The data mainly comes from the official statistical yearbook of Guangdong Province, statistical yearbook of multiple cities in the Greater Bay Area, the National Statistics Bureau official website, Statistics and Census Service official website of Macau S.A.R, Census and Statistics Department of Hong Kong S.A.R and Wind database.

\subsection{Equation Setting}

This article uses the stepwise method mentioned by Wen (2014) to verify the existence of the mediation effect. The specific methods are as follows: (1) First, perform regression on $\mathrm{Y}=\mathrm{cX}+\mathrm{e} 1$ to test whether the total benefit $\mathrm{c}$ is significant. If it is, proceed to the next step. Otherwise, the sample data fails to meet the conditions of the mediation effect test, and the test will be terminated; (2) Regress $\mathrm{M}=\mathrm{aX}+\mathrm{e} 2$ and $\mathrm{Y}=\mathrm{c}^{\prime} \mathrm{X}+\mathrm{bM}+\mathrm{e} 3$ to determine whether the coefficients $\mathrm{a}$ and $\mathrm{b}$ are both significant. If both $\mathrm{a}$ and $\mathrm{b}$ are significant, it can be concluded that a mediating effect exists. Otherwise, there is no mediating effect; (3) Determine whether the $c^{\prime}$ coefficient is significant. If it is, there is a partial mediating effect in the model. Otherwise, a complete mediating effect exists.

The purpose of the first step in the stepwise method is to calculate the total effect of X on Y; the second step aims to determine the significance of the coefficient product (i.e., ab) and to distinguish whether there is a mediating effect; the third step is conducted to distinguish whether the model is a fully intermediary model or a partial intermediary model.

Based on this model, this article will use technological innovation as an intermediary variable to test whether there is a mediation effect between financial agglomeration and export trade in the Greater Bay Area.

With further reference to the relevant theories of the mediating effect model and the empirical methods of Huang and Chen (2020), the models established in this article are as follows: 


$$
\begin{aligned}
& \ln E X_{i t}=e_{1}+a_{0} \ln L Q_{i t}+a_{1} \ln g_{i t}+a_{2} \ln L M_{i t}+a_{3} \ln I M_{i t}+a_{4} \ln N E R_{i t}+\varepsilon_{i j} \\
& \ln P A_{i t}=e_{2}+b_{o} \ln L Q_{i t}+b_{1} \ln g_{i t}+b_{2} \ln L M_{i t}+b_{3} \ln I M_{i t}+b_{4} \ln N E R_{i t}+\varepsilon_{i t} \\
& \ln E X=e_{3}+c_{o} \ln L Q_{i t}+c_{1} \ln P A_{i t}+c_{2} \ln g_{i t}+c_{3} \ln L M_{i t}+c_{4} \ln I M_{i t}+c_{5} \ln N E R_{i t}+\varepsilon_{i t}
\end{aligned}
$$

\subsection{Variable Definitions}

1) The explained variable is export trade volume (denoted as $E X$ ). This paper uses the logarithm of the export trade volume of each city as an indicator to measure the level of export trade.

2) The explanatory variable is the level of financial agglomeration (denoted as $L Q$ ). This paper selects the logarithm of financial agglomeration location quotient to measure the level of financial agglomeration in each city, which is derived from the following equation:

$$
L Q_{i t}=\frac{q_{i t} / \sum_{j=1}^{N} q_{j t}}{Q_{i t} / \sum_{j=1}^{N} Q_{j t}}
$$

In this formula, $q_{i t}$ denotes the output of financial industry in city $\mathrm{i}$ in the $\mathrm{t}^{\text {th }}$ year, $\sum_{j=1}^{N} q_{j t}$ denotes the total output of the Greater Bay Area in financial sector in the $\mathrm{t}^{\text {th }}$ year, $Q_{i t}$ denotes the total output of city i in the $\mathrm{t}^{\text {th }}$ year, $\sum_{j=1}^{N} Q_{j t}$ denotes the total output of the Greater Bay Area in the $\mathrm{t}^{\text {th }}$ year.

3) The mediator variable is the innovation level $(\ln P A)$. The number of patent applications of a particular region can effectively reflect the its innovation capability, hence this article selects the logarithm of the number of patent applications to measure the level of technological innovation of each city.

4) The control variables are the degree of government intervention, employment level, import and export trade level and currency exchange rate. The degree of government intervention(denoted as $\ln g_{i t}$ ) is measured using the logarithm of the ratio of government public budget expenditure to GDP. Employment level (denoted as $\ln L M_{i t}$ ) is measured by the logarithm of the number of employed population in each city. Import level (denoted as $\ln I M_{i t}$ ) is measured by the logarithm of the import trade volume. Currency exchange rate (denoted as $\ln N E R_{i t}$ ) is measured by the logarithm of the annual average exchange rate of RMB to the US dollar for mainland cities, or the logarithm of the annual average exchange rate of the annual average exchange rate of the Hong Kong dollar (or Macau Patacas) to the US dollar for Hong Kong S.A.R (or Macau S.A.R.).

\section{Empirical Results and Analysis}

The empirical test sequence is: firstly, keeping all control variables constant, examine the relation between location quotient and export trade (Regression of equation 1); secondly, introduce the mediator variable, technological innovation (i.e, patent numbers), and conduct a regression analysis using the location quotient to examine the existence of the technological innovation effect of financial agglomeration (Regression of equation 2); finally, use technological innovation and the level of financial agglomeration (i.e., location quotient) to explain the change of export trade volume (Regression of equation 3).

As the null hypothesis is rejected in the Hausman test, this paper uses a fixed effects model to improve the accuracy of the outcome.

Table 2. Equation (1) regression results

\begin{tabular}{cccc}
\hline Variables & Coefficient & Variables & Coefficient \\
\hline \multirow{2}{*}{$\operatorname{lnLQ}$} & $-1.040^{* * *}$ & \multirow{2}{*}{$\operatorname{lnLM}$} & $-1.172^{* *}$ \\
& $(0.124)$ & & $(0.520)$ \\
$\ln N E R$ & $-2.427^{* * *}$ & \multirow{2}{*}{$\ln$} & $0.308^{* *}$ \\
& $(0.719)$ & & $(0.145)$ \\
$\operatorname{lng}$ & $1.230^{* * *}$ & $\mathrm{C}$ & $23.65^{* * *}$ \\
& $(0.172)$ & & $(3.177)$ \\
\hline R-squared & & 0.590 & \\
\hline
\end{tabular}


Table 3. Equation (2) regression results

\begin{tabular}{cccc}
\hline Variables & Coefficient & Variables & Coefficient \\
\hline \multirow{2}{*}{$\operatorname{lnLQ}$} & $0.507^{* *}$ & & $3.766^{* * *}$ \\
& $(0.204)$ & $\operatorname{lnLM}$ & $(0.854)$ \\
$\ln \mathrm{l} E \mathrm{~N}$ & 1.137 & & 0.115 \\
& $(1.181)$ & $\operatorname{lnIM}$ & $(0.238)$ \\
$\operatorname{lng}$ & $1.865^{* * *}$ & & $-11.33^{* *}$ \\
& $(0.282)$ & $\mathrm{C}$ & $(5.220)$ \\
R-squared & & 0.671 & \\
\hline
\end{tabular}

Table 4. Equation (3) regression results

\begin{tabular}{cccc}
\hline Variables & Coefficient & Variables & Coefficient \\
\hline \multirow{2}{*}{$\operatorname{lnLQ}$} & $-1.216^{* * *}$ & \multirow{2}{*}{$\operatorname{lnLM}$} & $-2.476^{* * *}$ \\
& $(0.106)$ & & $(0.472)$ \\
$\operatorname{lnPA}$ & $0.346^{* * *}$ & $\operatorname{lnIM}$ & $0.269^{* *}$ \\
& $(0.0519)$ & & $(0.120)$ \\
$\operatorname{lnNER}$ & $-2.821^{* * *}$ & $\mathrm{C}$ & $27.57^{* * *}$ \\
& $(0.597)$ & & $(2.692)$ \\
$\operatorname{lng}$ & $0.584^{* * *}$ & & \\
\hline R-squared & $(0.172)$ & & \\
\hline
\end{tabular}

Table 5. Robustness test results

\begin{tabular}{cccc}
\hline Variables & Equation (1) & Equation (2) & Equation (3) \\
\hline \multirow{2}{*}{ LnR\&D } & & & $0.494 * * *$ \\
& & & $(-0.0574)$ \\
$\operatorname{lnLQ}$ & $-1.040^{* * *}$ & $0.499 * * *$ & $-1.287 * * *$ \\
& $(-0.124)$ & $(-0.167)$ & $(-0.0974)$ \\
$\ln$ NER & $-2.427 * * *$ & -0.648 & $-2.107 * * *$ \\
& $(-0.719)$ & $(-0.968)$ & $(-0.54)$ \\
$\operatorname{lng}$ & $1.230 * * *$ & $1.418 * * *$ & $0.529 * * *$ \\
& $(-0.172)$ & $(-0.232)$ & $(-0.153)$ \\
$\ln \mathrm{MM}$ & $-1.172 * *$ & $2.139 * * *$ & $-2.229 * * *$ \\
& $(-0.52)$ & $(-0.701)$ & $(-0.409)$ \\
$\operatorname{lnIM}$ & $0.308^{* *}$ & $0.622 * * *$ & 0.00123 \\
& $(-0.145)$ & $(-0.195)$ & $(-0.114)$ \\
C & $23.65 * * *$ & -3.374 & $25.31 * * *$ \\
& $(-3.177)$ & $(-4.281)$ & $(-2.391)$ \\
\hline
\end{tabular}

\subsection{Analysis of Regression Results of Equation (1)}

The results of the regression of equation (1) are shown in Table 2. It is worth noting that the total effect is significant (the coefficient of $\ln L Q$ is significant at the significance level of $1 \%$ ), hence the first premise of the existence of the mediation effect is satisfied. In addition, the coefficient of $\ln L Q$ is -1.040 (significant at the significance level of $1 \%$ ), suggesting that there is a negative correlation between locational quotient and the growth of export trade volume, that is to say, financial agglomeration in the Greater Bay Area inhibits the development of export trade. However, whether this effect is caused by the technological innovation effect of financial agglomeration is still uncertain, and further analysis is needed.

\subsection{Analysis of Regression Results of Equation (2)}

The results of the regression of equation (2) are shown in Table 3. It is worth noting that the coefficient of $\ln L Q$ is significant at the significance level of $5 \%$, which means another premise of the mediation effect test is satisfied. It can be indicated from the coefficient of $\ln L Q$ (0.507) that financial agglomeration can to a large extent facilitate technological advancement of a region. In other words, financial agglomeration brings about technological innovation effect, which helps to increase the technical value of exports from the Greater Bay Area. 


\subsection{Analysis of Regression Results of Equation (3)}

The results of the regression of equation (3) are shown in Table 4. It is noticeable that the coefficients of $\ln L Q$ and $\ln P A$ are both significant at the significance level of $1 \%$, that is to say, the direct and indirect effects brought by $\ln L Q$ and $\ln P A$ are significant. So far, the three steps of examining the intermediary effect have been completed. The results show that the intermediary effect is significant. Technological innovation is indeed an intermediary variable between the financial agglomeration and export trade in the Greater Bay Area and there is a partial intermediary effect.

It can be seen that the coefficient of $\ln L Q$ is -1.216 at a significant level of $1 \%$, which means that financial gatherings inhibit export trade; and the coefficient of $\ln P A$ is 0.346 at a significant level of $1 \%$, which means that innovation can promote export trade. It can be interpreted by the fact that export trade industry is facing transformation and upgrading in the Greater Bay Area. On the one hand, the traditional labor-intensive export trade is gradually decreasing due to rising labor costs. On the other hand, the technological innovation effect brought by financial agglomeration and the introduction of high-tech talents promotes the expansion of technology-intensive export trade the upgrading process of export trade.

\subsection{Robustness Test}

The intermediate variable selected in the empirical analysis is the innovation output, that is, the logarithm of the number of patent applications (lnPA). However, there is no unified conclusion about the selection of indicators measuring the innovation level. Therefore, in order to verify the robustness of the model, the innovation input indicator (i.e., the logarithm of $R \& D$ expenditure, $\ln R \& D$ ) is selected to conduct another regression, and the results are shown in Table 5.

It can be seen that the coefficient of $\operatorname{lnLQ}$ is -1.040 in equation (1), and 0.499 in equation (2). The coefficient of $\operatorname{lnLQ}$ is -1.287 and the coefficient of $\operatorname{lnR} \& D$ is 0.494 at the significance level of $1 \%$ in equation (3). The results satisfied the requirements of the establishment of a mediation effect mode, thus it can be concluded that the mediation effect exists. In addition, the coefficients of the key variables are basically the same as the previous regression results. Therefore, the model has passed the robustness test, and the results are highly reliable.

\subsection{Conclusion}

This paper uses the relevant data of the Guangdong-Hong Kong-Macau Greater Bay Area from 2009 to 2018 to establish a mediation model using innovation as an mediator variable. The innovation output indicator is then replaced with an innovation input indicator for robustness testing. The conclusions of this study are as follows:

1) Technological innovation can be considered as a mediator variable between financial agglomeration and export trade in the Greater Bay Area (i.e., there is indeed an intermediary effect). It can also be seen that financial agglomeration in the Bay Area can act on export trade by promoting innovation, hence changing the scale and structure of export trade;

2) Considering the Greater Bay Area as a whole, it has been found that financial agglomeration inhibits export trade to an extent. Although financial agglomeration can encourage innovation and thereby promote the industrial upgrading of export trade, the Greater Bay Area is still dominated by traditional labor-intensive product export, which is negatively influenced by innovative industry. Therefore, financial agglomeration inhibits export trade to a certain degree;

3) The Greater Bay Area has one of the most vibrant financial markets, which makes it increasingly attractive to talents all around the world. While being one of the major talent hubs promotes the development of innovative industries along the bay, the export trade of traditional labor-intensive industries is facing great challenges as they fail to provide decent salaries for global talents. To make things worse for such industries, the high income level and high spending power along the bay leads to high demand for imports, driving the net export even lower. This will eventually inhibit export trade in the area on one hand, but facilitate innovation-oriented industries on the other.

\section{Discussion}

Although financial agglomeration promotes innovation along the bay, it has hampered the future development of traditional, labor-intensive export industries, which remain to be one of the major engines of local economy. Therefore, this article proposes several solution to this problem:

1) Accelerate the development of financial agglomeration and promote the continuous improvement in innovation

Although empirical research has shown that financial agglomeration has an inhibitory effect on export trade, this effect may not be deleterious to the future development of the bay. On one hand, financial agglomeration will lead to a decrease in export trade, impairing regional economic performance in the short run. On the other hand, financial agglomeration can effectively promote innovation, leading to regional industrial upgrading and improved competence in technology-oriented industries. Along the Pacific Coast sits several world-class innovation hubs, including San Francisco Bay, Tokyo, Singapore and Shanghai. To compete with these world-class innovation hubs, accelerating the financial agglomeration process will certainly be helpful, as capital provides the cornerstone for technological 
prosperity.

2) Avoiding or alleviating unbalanced regional development

The development of the financial industry in the Greater Bay Area is highly unbalanced. Financial agglomeration level (measured in location quotient) of Hong Kong and Shenzhen far exceeds that of other cities, while finance industries in many other cities along the bay are rudimentary. Unbalanced development may not be beneficial in the long run. Factor prices, which measured the price of factors of production (including land, labor, technology, machinery etc.), tend to be higher than the average in major financial hubs such as London, New York and Hong Kong. Skyrocketed housing prices will create obstacles for technological innovation, leading to the crowding out of tech-oriented industries. Also, unbalanced development will hamper the development of surrounding areas of these financial centers, forcing more people to head into these financial hubs for job opportunity, which in turn leads to higher factor prices in financial centers. Therefore, measures that take the interests of financially underdeveloped cities will be necessary, such as helping those cities to attract investment, providing appropriate policy tools, and introducing high-quality talents to those areas.

3) Integrating finance and technology, and meeting financing needs of tech startups

Finance is the motivator of innovation, and innovation can, in turn, promote the development of finance. This important and complementary relation between finance and technology cannot be ignored. With the rapid development of technology all across the globe, demand for financial support by these tech startups has seen a tremendous growth, which cannot be satisfied by traditional financial framework. Thus, the Greater Bay Area has to pay attention to the cooperation between finance and technology. Only by providing new tech startups appropriate financial support, will technology and innovation continue to thrive. Finance is the foundation of innovation, and innovation can, in turn, promote the development of finance. This important and complementary relation between finance and technology cannot be overlooked. With the rapid development of technology all across the globe, demand for financial support by these tech startups has seen a tremendous growth, which cannot be satisfied by traditional financial framework. Thus, the Greater Bay Area has to pay attention to the cooperation between finance and technology. Only by providing new tech startups appropriate financial support, will technology and innovation continue to thrive. To achieve this, local authorities may have to propose innovative solutions to meet the funding requirements of new startups, as well as embrace some innovative financial products.

\section{References}

Huang, W. H., \& Chen, H. Y. (2020). How Does Financial Development Promote Industrial Upgrading in the Guangdong-Hong Kong-Macao Greater Bay Area: An Empirical Analysis on the Mediating Effect of Science and Technology Innovation[J]. Reform of Economic System, 4, 158-165.

Jin, Q. Q. (2012). The research on the efficiency of the financial agglomeration to promote technology innovation[D]. Hunan University, 2012.

Li, S. Q., \& Deng, X. L. (2017). Has Financial Agglomeration Promoted Technological Innovation?[J]. Journal of Nanjing Audit University, 14(5),102-111.

Li, X., Ran, G., \& Zheng, W. (2017). Financial development spatial correlation and regional innovation output. $R \& D$ Management, 29(1), 55-64.

Schumpeter, J. A. (1912).The theory of economy development. Cambrige, MA: Harvard Univerisity Press.

Wang, G. B., \& Guan, J. C. (2009). The impact of technology innovation on export performance [J]. Studies in Science of Science, 9. https://doi.org/10.1109/ICICISYS.2009.5358136

Wang, R. X., \& Bai, M. (2017). Can financial agglomeration improve the efficiency of technological innovation? Empirical evidence from China[J]. Inquiry into Economic Issues, 2017(1),139-148.

Wen, Z.L., \&Ye, B. J. (2014). Analyses of mediating effects: The development of methods and models. Advances in Psychological Science, 22(5), 731. https://doi.org/10.3724/SP.J.1042.2014.00731

Xiu, G. Y., Zhu, Y., \& Liu, Y. (2019). The Double Characteristics of Financial Agglomeration on Science and Technology Innovation Efficiency[J]. Science \& Technology Progress and Policy, 36(17), 122-127.

Yan, S. Y., \& Xu, X. J. (2019). Financial Industry Agglomeration, Technology Innovation and Regional Economic Growth -An Analysis based on PVAR Model of Panel Data at Provincial Level[J]. Petroleum Drilling Techniques, 2019(1), 103-109.

Yao, L. M., \& Fang, M. J. (2007). An Empirical Study on Whether Technological Innovation Promotes China's Export Trade[J]. International Business Research, 3, 12-17. 
Yu, D. X., \& Liu, H. Y. (2008). Research on the Impact of Independent Innovation Capability upon Export Trade in China - Based on Empirical Studies of Patent Applications Certified. Journal of International Trade, 3, 28-33.

Yu, G. S. (2011). An empirical study of the relationship between China's export trade and technological innovation—_ based on simultaneous equations[J]. Studies in Science of Science, 29(2), 300-305.

Zeng,Z.S. (2021). The influence of financial agglomeration on export trade in the Guangdong-Hong Kong-Macau Greater Bay Area[J]. CO-Operative Economy \& Science.

Zhang, T. D. (2019). Financial Agglomeration and Scientific and Technological Innovation:Promoting or Extruding?:A Study of Panel Threshold Based on 17 Prefectures in Hubei Province[J]. Science and Technology Management Research, 39(5), 8-14.

Zou, W. Y., Qi, P., \& Xu, H. L. (2008). The Effects of Exports on Technology Innovation: An Empirical Research on China [J]. Journal of Hunan University (Social Sciences), 4.

\section{Notes}

Note 1. Calculated based on various statistical yearbooks

Note 2. Derived from Guangdong-Hong Kong-Macao Greater Bay Area Synergy Innovation Development Report(2019)

Note 3. Calculated based on various statistical yearbooks

\section{Copyrights}

Copyright for this article is retained by the author(s), with first publication rights granted to the journal.

This is an open-access article distributed under the terms and conditions of the Creative Commons Attribution license which permits unrestricted use, distribution, and reproduction in any medium, provided the original work is properly cited. 